\title{
A novel small molecule, HK-156, inhibits lipopoly- saccharide-induced activation of NF-KB signaling and improves survival in mouse models of sepsis
}

\author{
Jian-ping FANG ${ }^{1, \#}$, Yang $\mathrm{LIU}^{2, \#}$, Jie LI ${ }^{1}$, Wen-feng LIAO ${ }^{1}$, You-hong $\mathrm{HU}^{2, *}$, Kan DING ${ }^{1, *}$ \\ ${ }^{1}$ Glycochemistry \& Glycobiology Lab, Shanghai Institute of Materia Medica, Chinese Academy of Sciences, Shanghai 201203 , \\ China; ${ }^{2}$ State Key Laboratory of Drug Research, Shanghai Institute of Materia Medica, Chinese Academy of Sciences, Shanghai \\ 201203, China
}

\begin{abstract}
Aim: To characterize a small molecule compound HK-156 as a novel inhibitor of the nuclear factor kB (NF-kB) signaling pathway. Methods: THP-1 monocytes and HEK293/hTLR4A-MD2-CD14 cells were tested. HK-156 and compound 809, an HK-156 analogue, were synthesized. A luciferase assay was used to evaluate the transcriptional activity of NF-kB. The levels of cytokines were measured with cytokine arrays, ELISA and quantitative PCR. An electrophoretic mobility shift assay (EMSA), immunofluorescence, Western blot and mass spectrometry were used to investigate the molecular mechanisms underlying the actions of the agent. BALB/c mice challenged with lipopolysaccharide (LPS, $15 \mathrm{mg} / \mathrm{kg}$, ip) were used as a mouse experimental endotoxemia model.

Results: In HEK293hTLR4/NF-KB-luc cells treated with LPS (1000 ng/mL), HK-156 inhibited the transcriptional activity of NF-kB in a concentration-dependent manner $\left(\mathrm{IC}_{50}=6.54 \pm 0.37 \mu \mathrm{mol} / \mathrm{L}\right)$. Pretreatment of THP-1 monocytes with HK-156 (5, 10 and $\left.20 \mu \mathrm{mol} / \mathrm{L}\right)$ significantly inhibited LPS-induced release and production of TNF- $\alpha$ and IL-1 $\beta$, attenuated LPS-induced translocation of NF-KB into the nucleus and its binding to DNA, and suppressed LPS-induced phosphorylation and degradation of IKB $\alpha$, and phosphorylation of IKK $\beta$ and TGFB-activated kinase (TAK1). Meanwhile, HK-156 (5, 10 and 20 mmol/L) slightly suppressed LPS-induced activation of p38. The effect of HK-156 on LPS-induced activation of NF-KB signaling was dependent on thiol groups of cysteines in upstream proteins. In mouse models of sepsis, pre-injection of HK-156 (50 mg/kg, iv) significantly inhibited TNF $\alpha$ production and reduced the mortality caused by the lethal dose of LPS.

Conclusion: HK-156 inhibits LPS-induced activation of NF-KB signaling by suppressing the phosphorylation of TAK1 in vitro, and exerts beneficial effects in a mouse sepsis model. HK-156 may therefore be a useful therapeutic agent for treating sepsis.
\end{abstract}

Keywords: HK-156; NF-KB; NF-KB inhibitor; monocyte; lipopolysaccharide; TAK1; IKKß; p38; sepsis

Acta Pharmacologica Sinica (2012) 33: 1204-1216; doi: 10.1038/aps.2012.56; published online 11 Jun 2012

\section{Introduction}

The nuclear factor $\mathrm{\kappa B}$ (NF-kB) family of transcription factors consists of five members in mammalian cells - p65/RelA, c-Rel, RelB, p50, and p52 - and these members can form homodimers or heterodimers ${ }^{[1]}$. Of the various dimeric combinations, the p50/p65 heterodimer is the most frequently detected. The activation of NF-KB is controlled by the IкB kinase (IKK) complex, which consists of two catalytic subunits, named IKK1/IKKa and IKK2/IKK $\beta$, and the NEMO/IKKY regulatory protein ${ }^{[2]}$. In resting cells, NF-KB is located in the

\footnotetext{
\#These authors contributed equally to this work.

* To whom correspondence should be addressed.

E-mail kding@mail.shcnc.ac.cn (Kan DING); yhhu@mail.shcnc.ac.cn (You-hong HU)

Received 2012-02-28 Accepted 2012-04-23
}

cytosol in complex with the inhibitory proteins of the ІкB family, mainly IKBa ${ }^{[1]}$. In the canonical activation pathway, following the presentation of stimuli such as lipopolysaccharide (LPS) or the cytokines tumor necrosis factor (TNF)a and interleukin (IL)-1 $\beta$, which act through different receptors, signal transduction leads to the activation of IKK $\beta$. IKK $\beta$ predominantly phosphorylates IKBa, leading to its subsequent ubiquitination and degradation by the proteasome. The NF-kB complex is then released and translocates into the nucleus, where it triggers the transcription of multiple proinflammatory genes, including cytokines, chemokines and adhesion molecules that are essential for both the innate and adaptive immune response through the binding of a cis-acting $\mathrm{kB}$ element ${ }^{[3]}$. $\mathrm{NF}-\mathrm{KB}$ is a central mediator of the human immune response. It has been demonstrated that a large variety of pathogens and cytokines activate NF-kB signaling, and almost all of the proin- 
flammatory cytokines that participate in the inflammatory and immune responses are target genes of NF- $\mathrm{KB}^{[4]}$. Furthermore, constitutively activated NF- $\mathrm{KB}$ is often found to be involved in the pathogenesis of inflammatory diseases ${ }^{[5]}$. Gene knockout and knock-in mice have further proven the important role of NF- $\mathrm{kB}$ in inflammation ${ }^{[6,7]}$. The inhibition of NF- $\mathrm{kB}$ activation is now widely recognized as a valid drug-targeting strategy to combat inflammatory disease ${ }^{[8-10]}$.

Sepsis is an acute inflammatory syndrome that leads to multiple organ failure and remains a leading cause of mortality and morbidity in intensive care units ${ }^{[1]}$. An uncontrolled hyperinflammatory response and inappropriate cytokine response during early sepsis have been proposed as the cause of the multiple organ dysfunction syndrome that occurs during sepsis. Control of inflammation during the early stages of sepsis may therefore reduce organ injury and prevent death after septic insult. Fatal clinical instances of sepsis were originally attributed to LPS or endotoxin, a major constituent of the outer membrane of Gram negative bacteria ${ }^{[12]}$. When a bacterial infection occurs, LPS is released into the lymphatic and circulatory systems, which induces the activation of monocytes and macrophages via the production of proinflammatory cytokines, including TNFa and IL-1 $\beta$, and initiates the pathogenetic process of sepsis ${ }^{[13]}$. Multiple signaling events, especially through the NF-kB signaling pathway, play a critical role in this process ${ }^{[14]}$. With the help of the LPS binding protein (LBP) and CD14, LPS is transferred to the toll like receptor (TLR) 4/MD-2 receptor complex, resulting in NF-KB activation via an early myeloid differentiation factor 88 (MyD88)-dependent pathway and a late Toll/Interleukin-1 receptor (TIR) domain-containing adapter-inducing interferon (IFN) $\beta$ (TRIF)-dependent pathway ${ }^{[2,15]}$. In the end, both pathways lead to the activation of TGF $\beta$-activated kinase 1 (TAK1) through phosphorylation ${ }^{[2,16]}$. Phosphorylated TAK1 kinase then directly phosphorylates the IKK $\beta$ subunit of the IKK complex to activate the canonical NF-KB pathway, giving rise to the expression of numerous proinflammatory genes that are known to play important roles in septic pathophysiology ${ }^{[15,17-20]}$. Proinflammatory cytokines such as TNFa and IL-1 $\beta$ also enlarge this cascade through positive feedback by activating NF- $\mathrm{kB}$ signaling through their respective receptors ${ }^{[2]}$. This unregulated systemic response progresses to multiple organ failure, which is associated with a high mortality rate in humans ${ }^{[14]}$. NF-KB activation has been proposed as a pathological mechanism of septic shock, and the inhibition of NF-kB activation has been suggested to be a useful strategy for the treatment of sepsis ${ }^{[14,21]}$.

Many inhibitors of the NF-kB pathway have been identified, including a variety of natural and synthetic molecules such as antioxidants, peptides, small RNA/DNA molecules, and flavonoids ${ }^{[22]}$. These compounds act on NF-KB signaling at different points and have been shown to have an anti-inflammatory effect in vitro and in vivo, including in sepsis ${ }^{[23]}$. Many clinically used anti-inflammatory drugs, such as glucocorticoids, non-steroidal anti-inflammatory drugs (NSAIDs), and other immunosuppressants, have also been shown to act as inhibi- tors of the NF-kB pathway ${ }^{[22]}$. Several thiol-reactive compounds, such as parthenolide, cyclopentenone prostanglandins, sesquiterpene lactones, certain epoxyquinoids and arsenite, have been shown to inhibit the activity of IKK $\beta$ or the binding of NF-kB to DNA, probably through direct conjugation to the thiol group of cysteine ${ }^{[22]}$. Many NF-kB inhibitors have been shown to reduce the expression of multiple proinflammatory genes, diminish intravascular coagulation, and eventually prevent multiple organ injury and improve survival in rodent models of septic shock ${ }^{[24]}$. However, because of the complex nature of sepsis, to date, activated protein $C$ is the only drug on the market ${ }^{[11,21]}$, although some TLR4 antagonists are still in clinical trials ${ }^{[25,26]}$.

In this study, we found the synthetic compound HK-156 (Figure 1A) to be a novel NF-kB inhibitor using cell-based screening assays. In addition, its mechanism of action and direct target were investigated in human monocytes. The protective effects of HK-156 against sepsis were also evaluated in a sepsis animal model challenged with a lethal dose of LPS.

\section{Materials and methods \\ Materials}

Phorbol-12-myristate-13-acetate (PMA) and LPS (isolated from E coli strain 055: B5) were purchased from Sigma-Aldrich (St Louis, MO, USA). Cytokine array and ELISA kits were from R\&D systems (Minneapolis, MN, USA). Antibodies for IKKa, IKK $\beta, \mathrm{p}$-IкBa, IкBa, p65, p-IKKa (Ser176)/IKK $\beta$ (Ser177), p-IKKa (Ser180)/IKK $\beta$ (Ser181), p-IKKa (Ser176, Ser180)/ IKK $\beta$ (Ser177, Ser181), p-TAK1, TAK1, Lamin A, p-p38, p38, p-ERK1/2, and ERK1/2 were obtained from Cell Signaling Technology (Danvers, MA, USA), and the $\beta$-actin antibody used as internal reference was from Sigma-Aldrich.

Compound HK-156 (N-(2-methylfuro[2,3-d]pyrimidin4-yl)acrylamide) (Figure 1A) and 809 (N-(2-methylfuro[2,3-d] pyrimidin-4-yl)propionamide) (Figure 1B) were synthesized according to the procedure described in the supplementary data (Supplementary Figure 1). Their structures were characterized by ${ }^{1} \mathrm{H}-\mathrm{NMR},{ }^{13} \mathrm{H}-\mathrm{NMR}$, and MS spectra (Supplementary Figure 2). The purity of them determined by HPLC was above $98 \%$. For in vitro experiments, HK-156 and compound 809 were dissolved in dimethylsulfoxide (DMSO) and diluted in cell culture medium at different concentrations as specified in the text. The final concentration of DMSO was less than or equal to $0.1 \% v / v$. For in vivo studies, HK-156 was prepared in a vehicle consisting of $10 \%$ DMSO and $10 \%$ Cremophor EL (Sigma-Aldrich) in normal saline (NS), whereas the vehicle without HK-156 was used in parallel as a control group.

\section{Cell culture and transfection}

THP-1 cells (American Type Culture Collection, Manassas, VA, USA) were cultured in RPMI-1640 (Thermo Scientific, Rockford, IL, USA) containing $0.05 \mathrm{mmol} / \mathrm{L} 2$-mercaptoethanol. HEK293/hTLR4A-MD2-CD14 cells stably transfected with the human TLR4A, MD2 and CD14 genes (Invivogen, San Diego, CA, USA) were cultured in DMEM (Thermo Scientific). The culture media were supplemented with $10 \%$ FBS and 100 
A<smiles>C=CC(=O)Nc1nc(C)nc2occc12</smiles>

HK-156
B<smiles>CCC(=O)Nc1nc(C)nc2occc12</smiles>

809
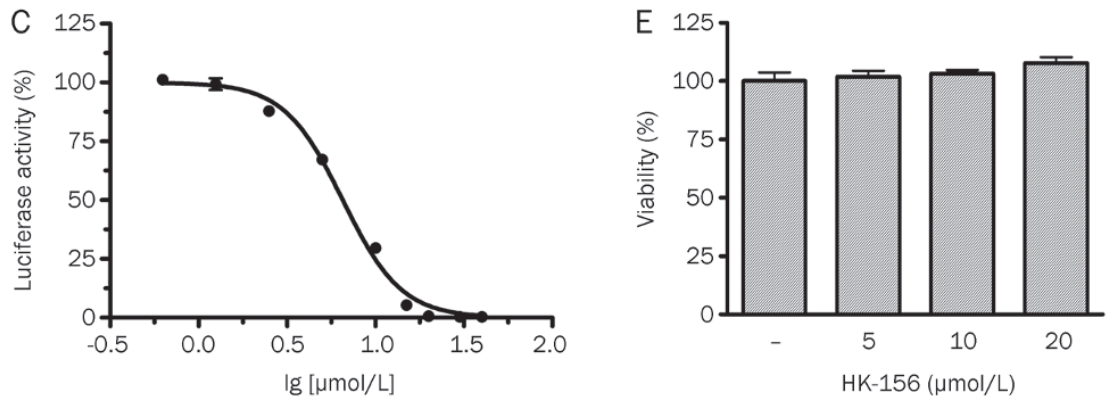

D
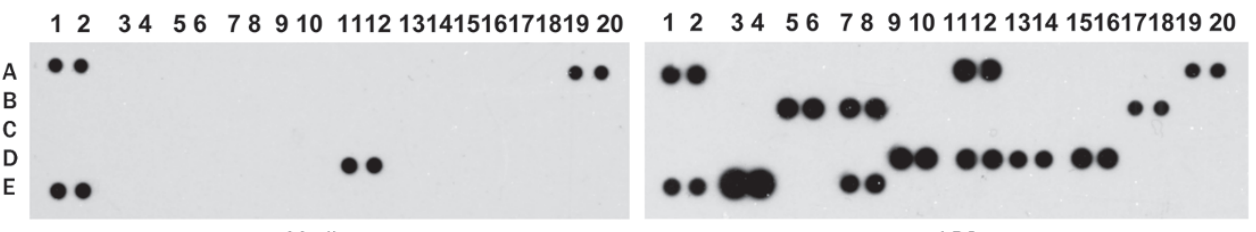

Medium

LPS

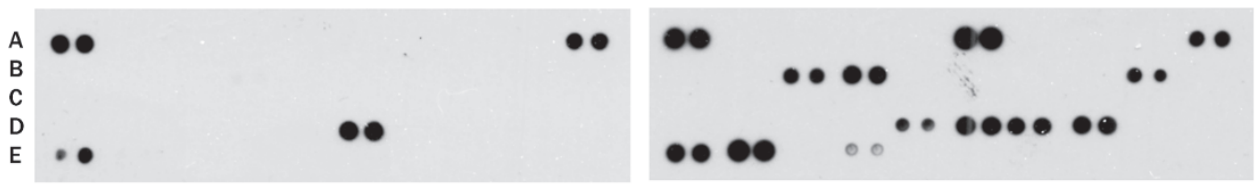

HK-156

HK-156+LPS

\begin{tabular}{ccccccccccc} 
& $\mathbf{1 2}$ & $\mathbf{3 4}$ & $\mathbf{5 6}$ & $\mathbf{7 8}$ & $\mathbf{9 1 0}$ & $\mathbf{1 1} \mathbf{1 2}$ & $\mathbf{1 3} \mathbf{1 4}$ & $\mathbf{1 5} \mathbf{1 6}$ & $\mathbf{1 7} 18$ & $\mathbf{1 9} 20$ \\
\hline A & POS & C5a & CD14Ligand & G-CSF & GM-CSF & GRO- $\alpha$ & I-309 & SICAM-1 & INF-Y & POS \\
B & - & IL-1 $\alpha$ & IL-1 $\beta$ & IL-1ra & IL-2 & IL-4 & IL-5 & IL-6 & IL-8 & - \\
C & - & IL-10 & IL-12p70 & IL-13 & IL-16 & IL-17 & IL-17E & IL-23 & IL-27 & - \\
D & - & IL-32 $\alpha$ & IP-10 & I-TAC & MCP-1 & MIF & MIP-1 $\alpha$ & MIP-1 & Serpin E1 & - \\
E & POS & RANTES & SDF-1 & TNF- $\alpha$ & STREM-1 & - & - & - & - & NEG
\end{tabular}

Figure 1. Dose response inhibition by HK-156 of NF-KB transcriptional activity. (A) Chemical structure of HK-156. (B) Chemical structure of compound 809. (C) After pretreatment with various doses of HK-156 (0.625, 1.25, 2.5, 5, 10, 15, 20, 30, and 40 $\mu \mathrm{mol} / \mathrm{L})$ for 20 min, HEK293hTLR4/NF-KBluc cells were treated with LPS $(1000 \mathrm{ng} / \mathrm{mL})$ in the presence or absence of HK-156 for $6 \mathrm{~h}$. The cell lysates were subjected to luciferase assays to evaluate the transcriptional activity of NF-KB. The results are expressed as relative luciferase activity compared with the cells treated with LPS alone and analyzed using the nonlinear regression curve-fitting program in GraphPad Prism software. Values represent mean \pm SEM. (D) After being pretreated with or without HK-156 (5 $\mathrm{mmol} / \mathrm{L})$ treatment for $20 \mathrm{~min}$, THP-1 monocytes were incubated with or without LPS (1000 ng/mL) in the presence or absence of HK-156 for $16 \mathrm{~h}$, followed by immunodetection of multiplex cytokines in the medium with cytokine array. The positions of the respective cytokines and controls on the array are shown below. (E) THP-1 monocytes were treated with the indicated concentration of HK-156 for $48 \mathrm{~h}$, and the cell viability was determined by a CCK-8 assay. Mean \pm SEM. $n=3$.

$\mathrm{U} / \mathrm{mL}$ penicillin plus $100 \mathrm{mg} / \mathrm{mL}$ streptomycin at $37^{\circ} \mathrm{C}$ in a humidified atmosphere containing $5 \% \mathrm{CO}_{2}$. Transfection of pNFKB-TA-Luc with co-transfection of pCDNA3.1 as a screening tag (Clontech, Mountain View, CA, USA) into HEK293/ hTLR4A-MD2-CD14 cells was performed using Lipofectamine 2000 (Invitrogen, Carlsbad, CA, USA). After reaching confluence, cells were split into complete medium with $0.8 \mathrm{mg} / \mathrm{mL}$ G418 (Merck KGaA, Darmstadt, Germany). Three weeks later, independent clones were isolated. Stable transfected clones were evaluated using NF- $\mathrm{KB}$ transcriptional activity assay with LPS (1000 ng/mL) as a stimulus. About 2 months later, stable cell line HEK293hTLR4/NF-kB-luc was achieved.

\section{NF-KB transcriptional activity assay}

The NF- $\mathrm{kB}$ transcriptional activity assay was performed with the NF-kB reporter plasmid stably transfected cell line HEK-
293hTLR4/NF-kB-luc using the Luciferase Assay System (Promega, Madison, WI, USA) according to the manufacturer's instructions. Briefly, untreated cells or cells that were incubated with the compound were lysed with CCLR buffer, and the cell lysates were transferred to Lumitrac 200 flat-bottomed 96-well plates (Greiner, Frickenhausen, Germany). The relative luciferase activity, recorded as relative light units (RLU), was read immediately after the substrate was added on a NOVOstar Microplate Reader (BMG Labtech, Offenburg, Germany). All experiments were performed in triplicate.

\section{Cell viability assay}

The cell viability after treatment with or without HK-156 was measured by a Cell Counting Kit-8 (CCK-8) assay following the manufacturer's instructions (Dojindo, Tokyo, Japan). THP- 1 cells were suspended at a final concentration of $1 \times 10^{5}$ 
cells/well and cultured in a 96-well flat-bottomed microplate. After exposure to HK-156 for $48 \mathrm{~h}$, CCK-8 $(10 \mu \mathrm{L})$ was added to each well, followed by incubation for $2 \mathrm{~h}$ at $37{ }^{\circ} \mathrm{C}$. Viable cells were counted by absorbance measurement at $450 \mathrm{~nm}$ using a NOVOstar Microplate Reader, and the viability was expressed as a percentage relative to untreated control cells. All experiments were performed in triplicate on three independent occasions.

\section{Immunodetection of cytokines}

Relative levels of complex cytokines in the medium of the cell culture or the serum of a mouse were measured using a cytokine array kit, while the quantitative cytokine contents were determined using sandwich ELISA kits for TNFa and IL-1 $\beta$ following the manufacturers' instructions. Briefly, cell cultures or sera were collected and centrifuged $(500 \times g)$ for 5 min. The supernatant was subjected to a cytokine array or ELISA assay.

RNA isolation and measurement of mRNA by quantitative realtime PCR

For real-time PCR, total RNA was isolated from monocytes with Trizol (Invitrogen) following the manufacturer's instructions. Briefly, 1-2 $\mu \mathrm{g}$ of total RNA was reverse transcribed to cDNA with MMLV reverse transcriptase (Takara, Otsu, Shiga, Japan) and diluted to a final volume of $100 \mu \mathrm{L}$. A $20 \mu \mathrm{L}$ reaction mixture containing $2 \mu \mathrm{L}$ of cDNA (20-60 ng) template, $0.25 \mu \mathrm{mol} / \mathrm{L}$ primers and $10 \mu \mathrm{L}$ SYBR Ex Taq Premix (Takara, Otsu, Shiga, Japan) was added to EU optical PCR tubes (Gene Chain Scientific, New York, USA) in a 96-well plate format. Real-time PCR was performed using an ABI 7500 Fast RealTime PCR system with the Sequence Detection software version 1.4 (Applied Biosystems, Foster City, CA, USA). The following primers were used: for TNFa: sense: $5^{\prime}$-GCTTGTTCCTCAGCCTCTTCT-3' and anti-sense: 5'-GGTTTGCTACAACATGGGCTA-3'; for IL-1 $\beta$ : sense: 5'-CCAGTGAAATGATGGCTTATTAC-3' and anti-sense: 5'-CTGTAGTGGTGGTCGGAGATT-3'. Conditions for amplification were $95^{\circ} \mathrm{C}$ for $10 \mathrm{~s}$ and 40 cycles of $95^{\circ} \mathrm{C}$ for $5 \mathrm{~s}$ followed by $60^{\circ} \mathrm{C}$ for $30 \mathrm{~s}$. The fold change of mRNA was evaluated by the relative copy number $(\mathrm{RCN})$ and expression ratios of selected genes normalized to the expression of the housekeeping gene GAPDH (primers: sense: 5'-ACTTTGGTATCGTGGAAGGACT-3' and anti-sense: 5'-GTAGAGGCAGGGATGATGTTCT-3') and calculated by the relative quantification method using Sequence Detection software with the equation $\mathrm{RCN}=2^{-\Delta \Delta \mathrm{Ct}}$, where $\Delta \mathrm{Ct}=\mathrm{Ct}_{\text {target }}-\mathrm{Ct}_{\text {reference, }}$ and $\Delta \Delta \mathrm{Ct}=\Delta \mathrm{Ct}_{\text {test sample }}-\Delta \mathrm{Ct}_{\text {calibrator sample }}$.

\section{Nuclear protein extraction and electrophoretic mobility shift} assay (EMSA)

Nuclear protein extraction was performed using the hypotonic method with a nuclear extraction kit according to the manufacturer's instructions (Active Motif, Carlsbad, CA, USA). Briefly, cells were resuspended in hypotonic buffer after being washed with ice-cold PBS containing phosphatase inhibitors and incubated on ice for $15 \mathrm{~min}$. Detergent was added, and the mixture was vortexed at the highest speed. After centrifugation, the nuclear pellet was resuspended in complete lysis buffer and rocked at $4{ }^{\circ} \mathrm{C}$ for 30 min with vortexing at intervals, followed by centrifugation at $14000 \times g$ for $10 \mathrm{~min}$. The supernatant contained the nuclear extract. After the concentration was determined by the BCA method (Beyotime, Haimen, China), the nuclear protein extract was subjected to EMSA following the manufacturer's instructions (Pierce, Rockford, IL, USA). In short, equivalent amounts of nuclear extracts $(10 \mu \mathrm{g}$ of protein) prepared from cells stimulated with LPS $(1000 \mathrm{ng} / \mathrm{mL})$ in the presence or absence of HK-156 for 20 min were incubated with a $5^{\prime}$-biotin end-labeled doublestranded NF-кB-specific probe (5'-AGTTGAGGGGACTTTCCCAGGC-3') synthesized by Sangon (Shanghai, China) and poly (dI-dC) in the presence or absence of a 100-fold excess of cold non-biotin labeled probe for the NF- $\mathrm{kB}$ p65 subunit for $20 \mathrm{~min}$ at room temperature. Samples were resolved on a native $4.5 \%$ polyacrylamide gel and transferred to a nylon membrane, followed by crosslinking at $120 \mathrm{~mJ} / \mathrm{cm}^{2}$ using an ultraviolet crosslinker (UVP, Upland, CA, USA). After blockade and incubation with streptavidin-conjugated HRP for 15 min, the membrane was exposed to the ECL substrate to detect biotin-labeled DNA bands.

\section{Immunoblotting}

Cells were lysed with SDS-PAGE sample loading buffer followed by denaturation at $95^{\circ} \mathrm{C}$ for $15 \mathrm{~min}$. After centrifugation, the supernatant protein samples were subjected to $10 \%$ SDS-PAGE and incubation with specific antibodies. After three washes, secondary antibodies were applied, and blots were developed.

\section{Immunofluorescence}

Nuclear translocation of the p65 subunit of NF-kB was examined by immunofluorescence. Briefly, THP-1 cells were induced to adhesion for $12 \mathrm{~h}$ with a low concentration of PMA (10 ng/mL), followed by treatment with HK-156 and LPS. The cells were fixed with $3 \%$ formaldehyde and permeabilized with ice-cold methanol. After washing with PBS, the slides were blocked with $3 \%$ bovine serum albumin in PBS/Triton (PBS/0.3\% Triton X-100) for $1 \mathrm{~h}$ and incubated with rabbit anti-p65 antibody diluted in PBS/Triton at $4{ }^{\circ} \mathrm{C}$ overnight. The cells were washed and incubated with AlexaFluor 488 goat anti-rabbit IgG antibody in PBS/Triton (1:200, Molecular Probe, Carlsbad, CA, USA) and propidium iodide (PI, 100 $\mu \mathrm{g} / \mathrm{mL}$, Sigma-Aldrich) for $1 \mathrm{~h}$. After staining, the cells were mounted with fluorescent mounting medium (Dako, Carpinteria, CA, USA) and observed with a Leica SP2 laser scanning confocal microscope (Leica Microsystems CMS GmbH, Mannheim, Germany).

\section{Conjugation of HK-156 with glutathione}

HK-156 $(20 \mathrm{nmol})$ in DMSO was incubated with 4 eq of reduced glutathione in $20 \mathrm{mmol} / \mathrm{L}$ Tris- $\mathrm{HCl}(\mathrm{pH} \mathrm{7.5)}$ for $1 \mathrm{~h}$ at $37^{\circ} \mathrm{C}$. The sample was directly injected into a LCQ Deca ion trap mass spectrometer (Thermo Finnigan), and mass spectra 
were recorded in ESI-positive mode.

\section{Animal test}

Female BALB/c mice, 6-8 weeks old, were purchased from the Shanghai SLAC Laboratory Animal Center and maintained in a specific pathogen-free (SPF) environment and used in accordance with approved regulations of the Institutional Animal Care and Use Committee of the Shanghai Institute of Materia Medica, Chinese Academy of Sciences (Approval ID: SIMM-AE-DK-2010-03) after $10 \mathrm{~d}$ of acclimatization. Mice were injected iv with HK-156 or vehicle consisting of $10 \%$ DMSO and $10 \%$ Cremophor EL in normal saline $2 \mathrm{~h}$ before the ip administration of a lethal dose of LPS $(15 \mathrm{mg} / \mathrm{kg})$ or normal saline. Mice were monitored hourly. In experiments used to determine the cytokine level, mice were treated with LPS and/or HK-156 as outlined above. Blood was drawn via a retro-orbital puncture at $2 \mathrm{~h}$ post challenge and clotted for 1 $\mathrm{h}$ at $4^{\circ} \mathrm{C}$. The serum was collected through centrifugation and stored at $-80^{\circ} \mathrm{C}$ for future analysis. A Mantel-Haenszel log rank test was performed, and a Kaplan-Meier survival curve was generated using Graph-Pad Prism (version 5.01 for Windows, GraphPad Software, www.graphpad.com).

\section{Statistical analysis}

All data were managed with GraphPad Prism 5.01 software and expressed as mean \pm SEM. The significance $(P$ value) of the difference was evaluated based on an unpaired Student's $t$ test for the comparison of two groups or a one-way ANOVA analysis method for multiple comparisons. Values of $P<0.05$ were considered statistically significant.

\section{Results}

HK-156 inhibits LPS induced transcriptional activation of NF-KB and cytokine release

To identify a new NF-kB signaling inhibitor, we established a cell-based screening panel on the stable cell line HEK293hTLR4/NF-kB-luc. Using LPS as an inducer and luciferase as a reporter gene, we found that the novel small molecule HK-156 (Figure 1A) significantly inhibited NF-KB transcriptional activation stimulated by LPS in a dose-dependent manner. When pretreated with HK-156 for $20 \mathrm{~min}$ and cocultured with LPS $(1 \mu \mathrm{g} / \mathrm{mL})$ for another $6 \mathrm{~h}$, the half inhibitory concentration $\left(\mathrm{IC}_{50}\right.$ ) was $6.54 \pm 0.37 \mu \mathrm{mol} / \mathrm{L}$ (Figure $1 \mathrm{C}$ ). When the cell viability was evaluated with MTT, HK-156 had no observable effect on the proliferation of HEK293hTLR4/NF-kB-luc cells at concentrations up to $40 \mu \mathrm{mol} / \mathrm{L}$ (data not shown). These results showed that HK-156 was a significant NF-кB signaling inhibitor based on HEK293hTLR4/NF-KB-luc cells treated with LPS.

Inhibition of NF-kB activation should lead to the attenuation of the transcription and expression of target genes regulated by NF-кB. To evaluate whether this occurs, human THP-1 monocytes were pretreated with HK-156 (5 $\mu \mathrm{mol} / \mathrm{L})$ and cocultured with LPS $(1 \mu \mathrm{g} / \mathrm{mL})$ for $16 \mathrm{~h}$. The medium was then subjected to a cytokine array assay. We found that the release of cytokines such as GROa, IL-1 $\beta$, IL-1ra, IL-8, MCP-1,
MIP-1a, MIP-1 $\beta$, RANTES, and TNFa induced by LPS was inhibited to different degrees, and IL-1 $\beta$, RANTES, and TNFa were most obviously attenuated (Figure 1D). In comparison with the control medium group, HK-156 treatment alone did not induce any cytokines other than MIF in the medium, which was considered to be background (Figure 1D). As all of the cytokines above are target genes of NF- $\mathrm{KB}^{[4]}$, which indicated that HK-156 could inhibit NF-KB targeted cytokine release in LPS-induced THP-1 cells.

To determine whether the ability of HK-156 to reduce the release of proinflammatory cytokines was caused by its cytotoxicity, the CCK-8 method was employed to evaluate cell survival. As shown in Figure 1E, the viability of THP-1 cells treated by HK-156 at a concentration of $20 \mu \mathrm{mol} / \mathrm{L}$ for $48 \mathrm{~h}$ was almost the same as that of untreated cells, suggesting that HK-156 had no observable effect on cell survival, at least at concentrations less than $20 \mu \mathrm{mol} / \mathrm{L}$.

All of these experiments indicated that HK-156 inhibited the transcriptional activation of NF- $\mathrm{kB}$ and the release of several NF-kB targeted inflammatory cytokines stimulated by LPS.

\section{HK-156 arrests the release and production of inflammatory cytokines in THP-1 monocytes stimulated by LPS}

To further quantitatively evaluate the effect of HK-156 on cytokine release in THP-1 cells stimulated by LPS, the ELISA method was adopted, and different concentrations of HK-156 were used. We found that TNFa and IL-1 $\beta$ release was dramatically induced by LPS and was undetectable in untreated THP-1 cells. However, when pretreated with HK-156, the release of cytokines was significantly reduced in a dose-dependent manner, and $20 \mu \mathrm{mol} / \mathrm{L}$ of HK-156 almost completely abrogated the release of TNFa and IL-1 $\beta$ (Figure 2A and 2B). In addition, HK-156 alone had no effect on the release of TNFa and IL-1 $\beta$ (Figure 2A and 2B).

Next, to determine the level at which HK-156 affected the production of proinflammatory cytokines, we compared the mRNA levels of inflammatory cytokines in THP-1 monocytes. Real-time PCR was performed after the mRNA was isolated from untreated THP-1 monocytes, monocytes treated with LPS alone $(1000 \mathrm{ng} / \mathrm{mL})$, pretreated with different concentrations of HK-156 and cocultured with LPS, or treated with HK-156 alone $(20 \mu \mathrm{mol} / \mathrm{L})$ for $2 \mathrm{~h}$. Compared with untreated monocytes, an 80 -fold increase in TNFa was induced by LPS. The accumulation of TNFa mRNA after stimulation by LPS was decreased by HK-156 in a dose-dependent manner (Figure 2C). Similarly, the production of IL-1 $\beta$ mRNAs in LPS-stimulated monocytes was also inhibited by HK-156 in a dose-dependent manner, by 2000 -fold in some cases (Figure 2D). Moreover, treatment with $20 \mu \mathrm{mol} / \mathrm{L}$ of HK-156 almost completely abrogated the accumulation of both proinflammatory cytokine mRNAs from LPS-stimulated THP-1 monocytes (Figure 2C and 2D). These experiments indicated that HK-156 affected the transcript levels of the previously described proinflammatory cytokines.

Taken together, these results indicated that HK-156 inhibited the release and production of inflammatory cytokines 

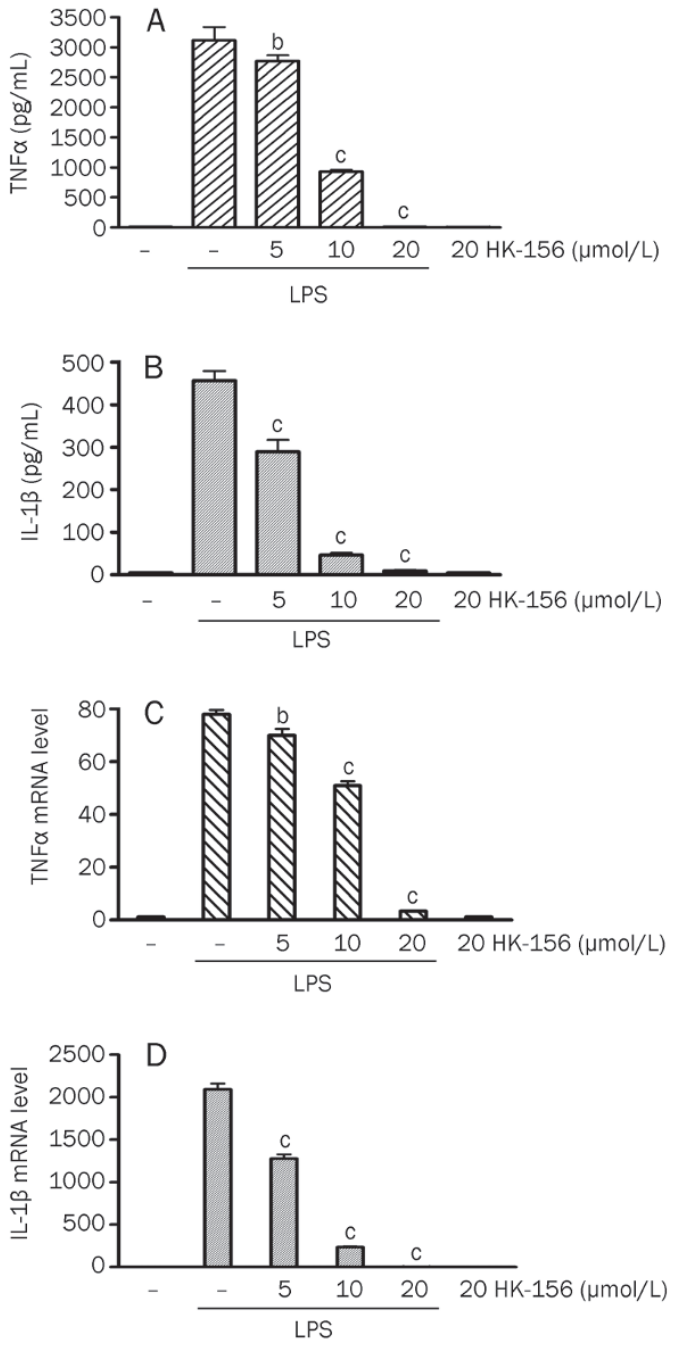

Figure 2. Effect of HK-156 on the release and production of inflammatory cytokines. (A-B) THP-1 monocytes were pretreated with or without different doses of HK-156 for 20 min, followed by the addition of LPS $(1000 \mathrm{ng} / \mathrm{mL})$ or PBS to incubate for another $16 \mathrm{~h}$. The supernatant of the medium was collected and subjected to immunodetection of TNF $\alpha$ (A) and IL-1 $\beta$ (B) with an ELISA kit. (C-D) THP-1 monocytes were pretreated with or without the indicated doses of HK-156 20 min prior to the addition of LPS (1000 ng/mL) or PBS for another $2 \mathrm{~h}$, then total RNA was isolated and the mRNA levels of TNF $\alpha(C)$ and IL-1 $\beta$ (D) were determined by quantitative real-time PCR. Values represent mean \pm SEM $\left(n=3 ;{ }^{\mathrm{b}} P<0.05\right.$, ${ }^{\mathrm{c}} P<0.01$ compared with LPS treatment alone).

in human THP-1 monocytes at the protein and mRNA levels when stimulated by LPS.

HK-156 impairs LPS-induced translocation of NF-KB complex into the nucleus and the formation of an NF-KB-DNA complex

Canonical NF-KB pathway activation by LPS results in the translocation of the NF-KB complex from the cytosol into the nucleus to bind the DNA of target genes and initiate the transcription and expression of proinflammatory cytokines. Since HK-156 inhibited the transcriptional activation of NF-KB in HEK293hTLR4/NF-KB-luc cells induced by LPS and the release and production of TNFa and IL-1 $\beta$ in THP-1 cells stimulated by LPS, we asked if HK-156 could inhibit LPS-induced translocation of the NF-kB complex into the nucleus and its binding to DNA. To address this question, after 20 min pretreatment with or without different doses of HK-156, THP-1 cells were stimulated with or without LPS for another $20 \mathrm{~min}$, and then nuclear extracts were prepared and analyzed by EMSA. We found that HK-156 significantly inhibited the formation of the NF-kB-DNA complex in LPS-stimulated human monocytes in a dose-dependent manner, and HK-156 did not induce the DNA-binding activity of NF-kB (Figure 3A). Next, we investigated whether HK-156 directly interfered with the interaction of NF-KB and DNA or inhibited the translocation

A

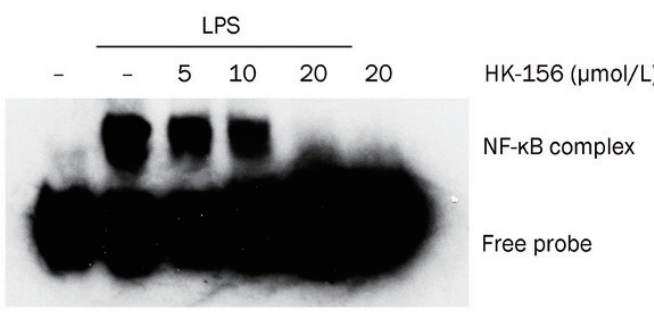

B

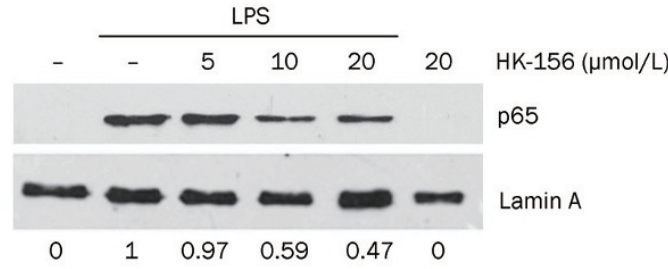

C
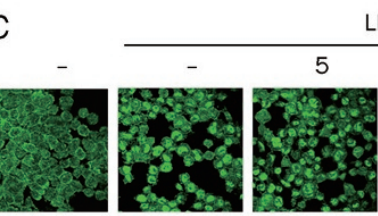

LPS
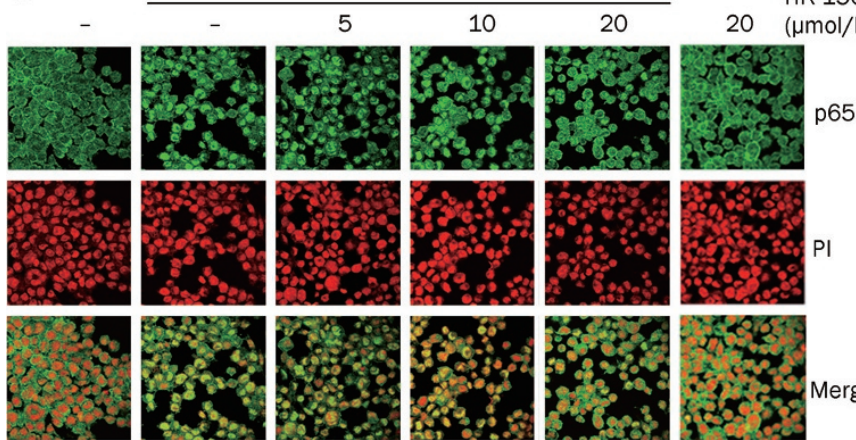

Figure 3. Effect of HK-156 on LPS-induced translocation of NF-KB complex into the nucleus and its binding to DNA. (A-B) THP-1 monocytes were pretreated with or without different doses of HK-156 for 20 min, followed by the addition of LPS $(1000 \mathrm{ng} / \mathrm{mL})$ or PBS and incubated for another $20 \mathrm{~min}$. The cells were lysed and nuclear protein was extracted, followed by an (A) EMSA assay, or (B) immunoblotting assay with anti-p65 antibody, whereas equal protein loading was verified using an anti-Lamin $A$ antibody. The numbers below the blots depict densitometric values (ratio of p65/Lamin A, normalized to LPS treated alone). (C) After adhesion onto a cover slip was induced by PMA (10 ng/mL) for $12 \mathrm{~h}$, THP-1 monocytes were treated as described above. The cells were then fixed, stained with a monoclonal anti-p65 antibody (upper panel, green) and examined by confocal microscopy. Merged images with nuclei counterstaining with PI (middle panel, red) are shown in the lower panels. 
of NF-kB complex into the nucleus, leading to the decreased accumulation of NF-kB in nucleus. For this purpose, nuclear lysates from THP-1 monocytes treated as described above were analyzed by immunoblotting. As shown in Figure 3B, the p65 subunit of the NF-kB complex translocated into the nucleus upon stimulation by LPS. In addition, HK-156 could significantly inhibit the translocation in a dose-dependent manner, and HK-156 alone could not induce the translocation of NF-kB complex into nucleus. The dose-dependent inhibitory effect of HK-156 on the translocation of NF-KB complex into the nucleus was further confirmed by immunofluorescence (Figure 3C). These results demonstrated that HK-156 could inhibit the LPS-induced translocation of NF-kB complex into the nucleus and subsequent binding to DNA in THP-1 cells in a dose-dependent manner, but HK-156 alone had no effect.

\section{Effect of HK-156 on LPS-activated NF-KB and MAPKs signaling pathways}

HK-156 could inhibit the LPS-induced translocation of NF-KB complex into the nucleus, which suggested that HK-156 might inhibit the activation of the NF-KB pathway upstream of the NF-кB complex. To examine the molecular mechanisms by which HK-156 inhibited the LPS-stimulated translocation of NF-KB complex into the nucleus in THP-1 monocytes and to determine the target of HK-156, we investigated the effect of HK-156 on the components of the NF-KB signaling pathway from the downstream targets to the upstream regulators along LPS/TLR4/NF-kB.

First, to determine whether the inhibitory effect of HK-156 on the translocation of NF-KB complex into the nucleus induced by LPS resulted from direct interference with the translocation of NF-kB complex or the inhibition of the activation of upstream regulators, THP-1 monocytes pretreated with different doses of HK-156 (0, 5, 10, and $20 \mu \mathrm{mol} / \mathrm{L})$ for $20 \mathrm{~min}$ were incubated with LPS (1000 ng/mL) for another $20 \mathrm{~min}$, and cell lysates were subjected to immunoblotting assay. We found that the phosphorylation of IкBa stimulated by LPS was significantly inhibited by HK-156, leading to the reduced degradation of IKBa (Figure 4A). When phosphorylation of the IKK complex was detected, HK-156 blocked the LPS-induced phosphorylation of IKK $\beta$ at Serine181, Serine177 or both simultaneously (Figure 4A). However, the induction of phosphorylation of IKKa at Ser180 by HK-156 in a dose-dependent manner was also observed (Figure 4A). Furthermore, TAK1 phosphorylation as a result of LPS stimulation was also inhibited by HK-156 in a dose-dependent manner (Figure $4 \mathrm{~A})$. Treatment with HK-156 alone $(20 \mu \mathrm{mol} / \mathrm{L})$ had no effect on the activation of the NF- $\mathrm{KB}$ signaling pathway other than phosphorylation of IKKa at Ser180 (Figure 4A).

Second, mitogen-activated protein kinases (MAPKs) are families of serine/threonine protein kinases, including c-Jun $\mathrm{NH}_{2}$-terminal kinase (JNK), ERK, and p38. MAPK signaling is another important signaling pathway induced by LPS ${ }^{[15,17]}$. To explore whether HK-156 affected LPS-induced MAPK signaling, THP-1 monocytes were lysed and subjected to an immu-
A
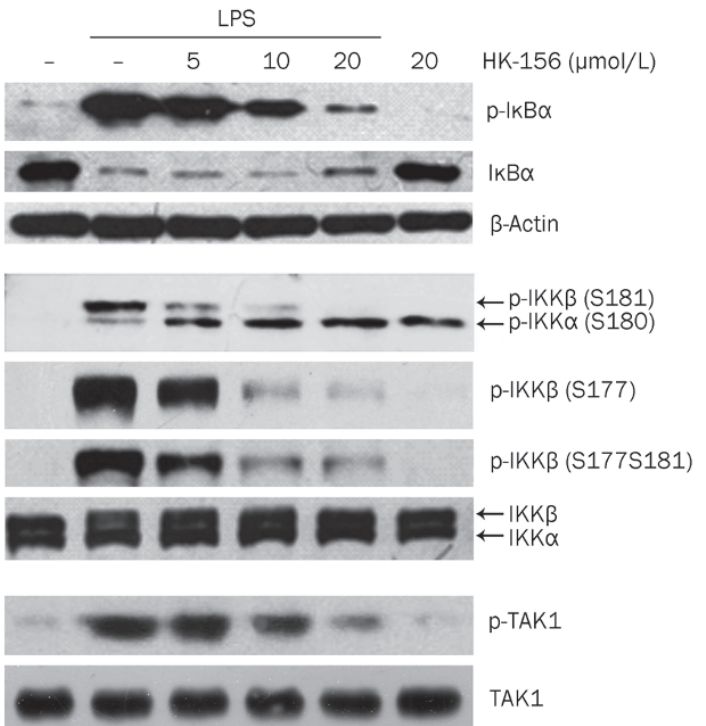

B
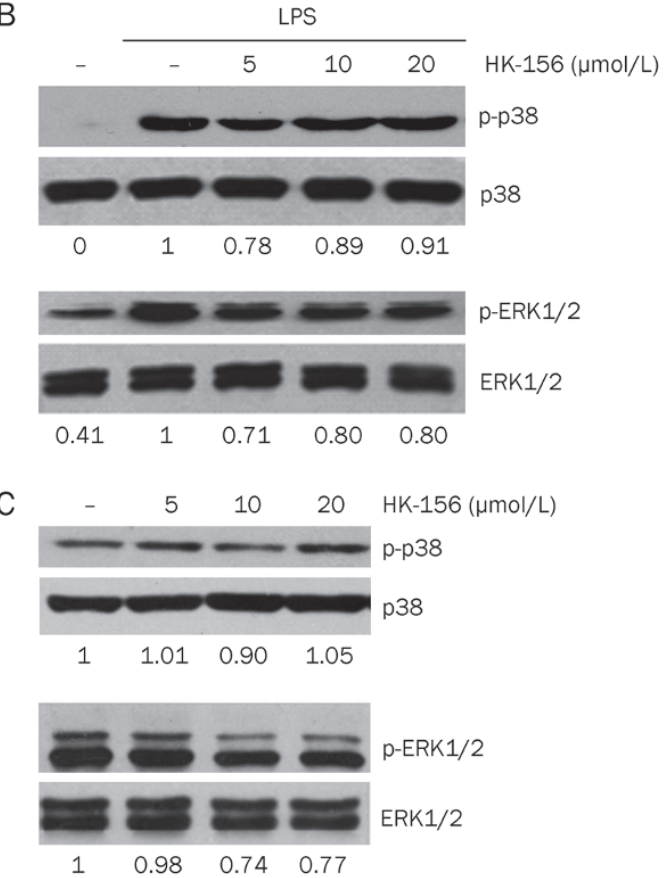

Figure 4. Effect of HK-156 on LPS-activated NF-KB and MAPKs signaling pathways. (A) THP-1 monocytes were pretreated with or without different doses of HK-156 for 20 min, followed by the addition of LPS $(1 \mu \mathrm{g} / \mathrm{mL}$ ) or PBS and incubated for another $20 \mathrm{~min}$. The cells were lysed and subjected to an immunoblotting assay with anti-p-ІкB $\alpha, \operatorname{IkB} \alpha, p-\mathrm{IKK} \beta$ (Ser181)/p-IKK $\alpha$ (Ser180), p-IKK $\beta$ (Ser177), p-IKK $\beta$ (Ser177Ser181), and $\mathrm{p}$-TAK1 antibodies. The expression of $\beta$-actin, IKK $/ \mathrm{IKK} \alpha$, or TAK1, respectively, served as the loading control. (B) The cells were treated with HK-156 and LPS as described in (A), followed by an immunoblotting assay probed by $\mathrm{p}-\mathrm{p} 38$ and $\mathrm{p}$-ERK1/2 antibodies, whereas total p38 and total ERK1/2, respectively, served as controls. The numbers below the blots depict densitometric values (ratio of p-p38 to p38 or p-ERK1/2 to ERK1/2, respectively, normalized to LPS treated alone). (C) Lysates of THP-1 monocytes treated with the indicated doses of HK-156 for 20 min were subjected to immunoblotting with p-p38 or p-ERK1/2 antibodies, whereas total p38 and total ERK1/2, respectively, served as controls. The numbers below the blots depict the densiometric values (ratio of p-p38 to p38 or p-ERK1/2 to ERK1/2, respectively, normalized to control). 
noblotting assay after pretreatment by HK-156 $(0,5,10$, and $20 \mu \mathrm{mol} / \mathrm{L})$ for $20 \mathrm{~min}$ prior to the addition of LPS $(1 \mu \mathrm{g} / \mathrm{mL})$ for another $20 \mathrm{~min}$. As shown in Figure 4B, the phosphorylation of both p38 and ERK1/2 induced by LPS was slightly inhibited by treatment of HK-156. Meanwhile, when the cells were treated with HK-156 in the absence of LPS at various concentrations $(0,5,10$, and $20 \mu \mathrm{mol} / \mathrm{L})$, the phosphorylation of p38 was not apparently altered, but the phosphorylation of ERK1/2 was slightly decreased (Figure 4C). Considering that HK-156 could inhibit the phosphorylation of ERK1/2 to almost the same degree when THP-1 cells were treated with or without LPS, HK-156 itself might have no influence on the phosphorylation of ERK1/2 induced by LPS.

Overall, HK-156 blocked LPS activated NF-кB signaling through inhibiting the phosphorylation of TAK1 and slightly inhibiting p38 signaling induced by LPS, whereas it might not affect the phosphorylation of ERK1/2 stimulated by LPS.

\section{Effect of HK-156 on LPS-induced activation of NF-KB signaling is thiol dependent}

Considering the structure of HK-156 (Figure 1A), HK-156 is a Michael reaction acceptor molecule because it has an $\alpha, \beta$ unsaturated carbonyl group. We speculated that the $\alpha, \beta-$ unsaturated carbonyl group is the functional group. To address this question, compound 809, an HK-156 analogue with only a carbonyl group, was used as a reference. As shown in Figure 5A, compound 809 could not inhibit LPSinduced transcription activation of NF-KB. This result suggested that the $\alpha, \beta$-unsaturated carbonyl group is required for HK-156 to have an effect on the activation of the NF-KB pathway. Furthermore, as $\alpha, \beta$-unsaturated carbonyl groups react with thiols, it is possible that the inhibition of the LPS-based activation of the NF-KB pathway by HK-156 was through a reaction with thiol groups of the cysteines in the component proteins of the NF-kB pathway. If so, other thiol-containing reagents might compete with HK-156 for the cysteines of the target protein(s) and alleviate the effects of HK-156 on the LPS-induced activation of the NF- $\mathrm{kB}$ pathway. As shown in Figure $5 \mathrm{~B}$, the inhibition of the LPS-induced transcriptional activation of NF-KB by HK-156 was indeed abrogated in the presence of the thiol-containing reagent reduced glutathione (GSH). Furthermore, the HK-156-mediated inhibition of LPSinduced IKK $\beta$ and IKBa phosphorylation was also abolished in the presence of GSH (Figure 5C), as was the inhibition of LPS-induced TNFa release (Figure 5D). In addition, the reference compound $\mathbf{8 0 9}$ did not alter the LPS-induced phosphorylation of IKK $\beta$ and IKBa or the release of TNFa. These results showed that HK-156 inhibited the LPS-induced NF-KB signaling pathway through interacting with the cysteine thiol groups of an unknown protein upstream of the IKK complex. To further understand the HK-156-thiol interaction, HK-156 was incubated with GSH, and the products were examined using mass spectrometry (MS). The analysis detected one major component at $m / z 511.3[\mathrm{HK}-156+\mathrm{GSH}+\mathrm{H}]^{+}$, indicating the addition of one molecule of GSH to one molecule of HK-156 (Figure 5D). The proposed reaction site of HK-156 is illustrated in Figure 5D.

Taken together, the results provided strong evidence indicating that a Michael reaction acceptor is required for the inhibitory activity of HK-156 against NF-kB signaling, and this group reacts with thiols and inhibits the LPS-induced activation of the NF-kB signaling pathway.

\section{HK-156 inhibits LPS-induced secretion of TNF $\alpha$ in vivo and} increases mouse survival in a model of sepsis

Because HK-156 efficiently inhibited the LPS-induced activation of the NF-kB pathway and the release of proinflammatory cytokines in vitro, we next investigated whether HK-156 could reduce the secretion of proinflammatory cytokines in vivo and be effective in protecting mice from lethality in a mouse endotoxemia model of sepsis as a model of systemic inflammation. BALB/c mice were injected iv with different doses of HK-156 $(10,30$, and $50 \mathrm{mg} / \mathrm{kg})$ or vehicle control, and $2 \mathrm{~h}$ later they were challenged ip with LPS $(15 \mathrm{mg} / \mathrm{kg})$ or NS. Mice that received HK-156 alone had no detectable serum TNFa. However, pretreatment of mice with HK-156 before the LPS challenge attenuated the increase in serum TNFa levels elicited after $2 \mathrm{~h}$ of LPS challenge in a dose-dependent manner, with treatment of $50 \mathrm{mg} / \mathrm{kg}$ of HK-156 yielding statistically significant results (Figure 6A, $8174 \pm 1872 \mathrm{pg} / \mathrm{mL}$ for the LPS group vs $1146 \pm 444 \mathrm{pg} / \mathrm{mL}$ for the HK-156 plus LPS group, $n=3,12$ animals per treatment. $P<0.05)$. When the relative cytokine level in the serum was further detected with a cytokine array assay, as shown in Figure 6B, HK-156 alone had no effect on the induced serum cytokine release, whereas LPS induced the secretion of many proinflammatory cytokines, including G-CSF, IL-6, MIP-1, TNFa, and RANTES ${ }^{[27]}$. Pretreatment of mice with HK-156 (50 mg/ kg) attenuated the increase of some of these cytokines and reduced the TNFa level in the serum (Figure 6B).

We next investigated whether HK-156 could increase the survival of mice treated with a lethal dose of LPS. Animals were injected iv with $50 \mathrm{mg} / \mathrm{kg}$ of HK-156 (or vehicle control) $2 \mathrm{~h}$ prior to injecting a lethal dose of LPS (as described above). Mice receiving HK-156 alone exhibited no lethality. In contrast, all of the mice that received LPS alone died within $69 \mathrm{~h}$ post challenge. Pretreatment with HK-156 resulted in an extended survival time of up to $200 \mathrm{~h}$ in $25 \%$ of the mice (Figure 6C).

These results suggested that HK-156 inhibited the LPSinduced secretion of TNFa in vivo and enhanced survival in a mouse model of sepsis.

\section{Discussion}

Accumulating evidence indicates that constitutively activated NF-kB signaling and uncontrolled expression of proinflammatory cytokines are correlated with the pathogenesis of inflammatory disease. The inhibition of NF-kB signaling has become a well-recognized strategy for anti-inflammatory therapy. In the present study, using an NF-kB luciferase reporter system consisting of the stably transfected cell line HEK293hTLR4/ NF-kB-luc, we found that the small molecule HK-156 could 
A

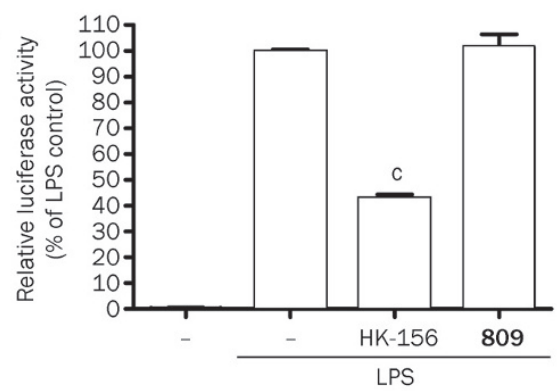

C

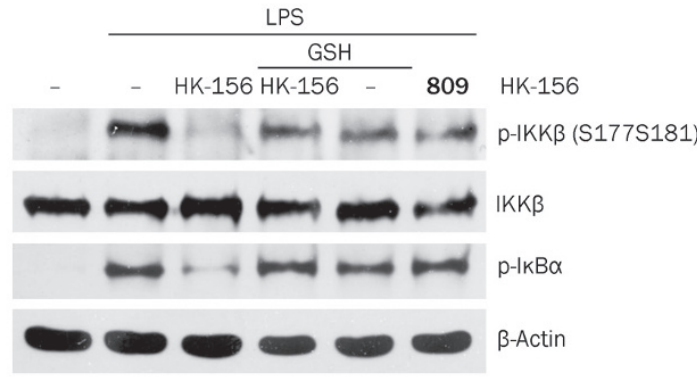

B

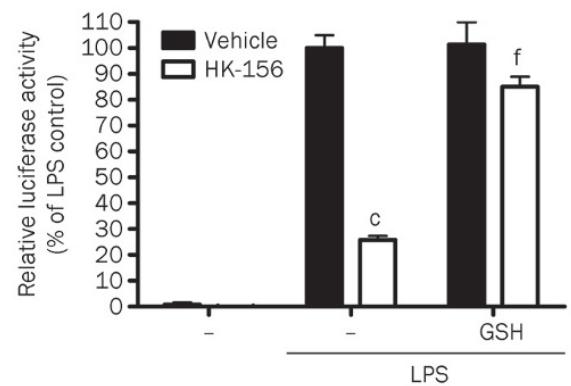

D

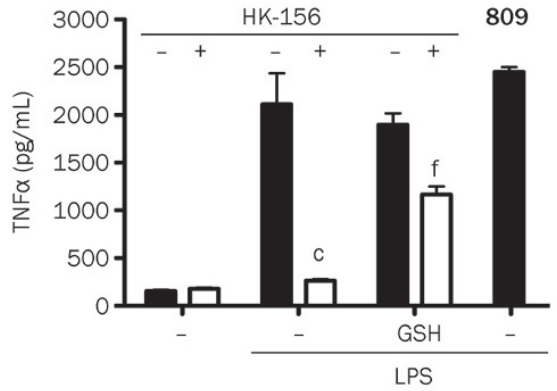

E

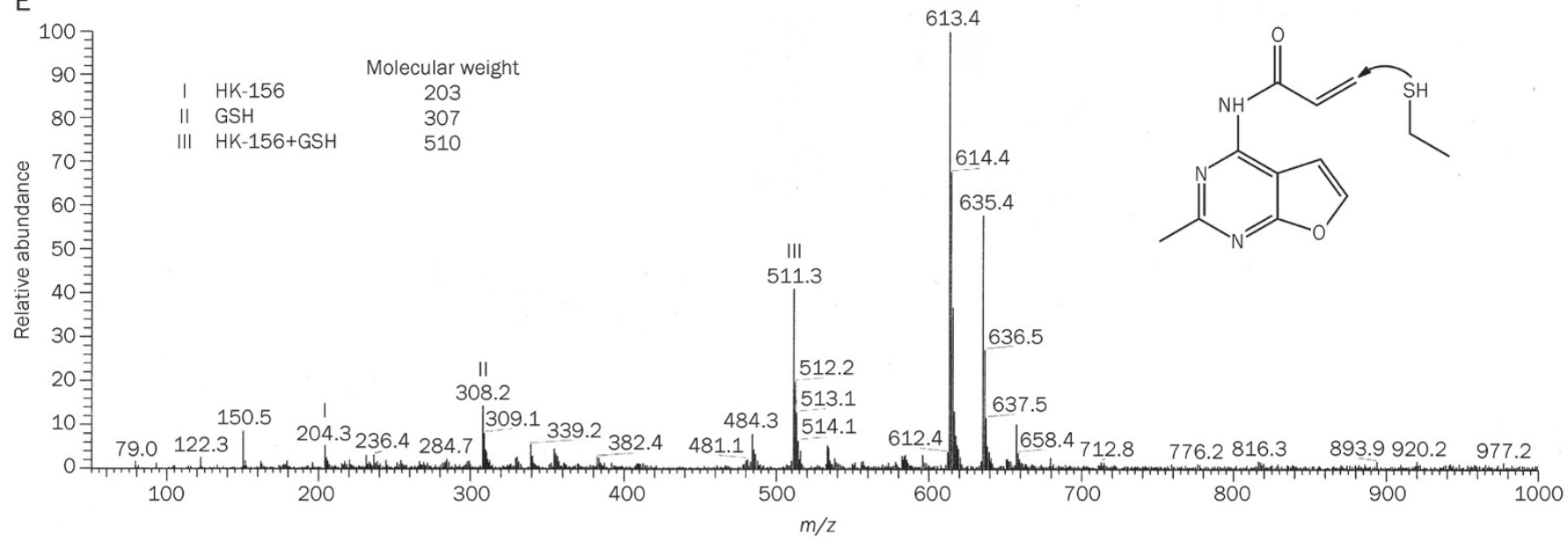

Figure 5. Inhibition of LPS/NF-KB signaling by HK-156 is thiol dependent. (A) HEK293hTLR4/NF-KB-luc cells were pretreated with HK-156 (10 $\mu$ mol/L) or $\mathbf{8 0 9}(10 \mu \mathrm{mol} / \mathrm{L})$ for $20 \mathrm{~min}$ and then stimulated with LPS for $6 \mathrm{~h}$. Cells were harvested for the luciferase assay. (B) HEK293hTLR4/NF-KB-luc cells were pretreated with GSH, HK-156 (10 $\mu \mathrm{mol} / \mathrm{L})$ or a mixture (HK-156 and GSH were premixed for $1 \mathrm{~h}$ at $\left.37^{\circ} \mathrm{C}\right)$ for 20 min and then stimulated with LPS for $6 \mathrm{~h}$. Cells were harvested for the luciferase assay. (C) THP-1 cells were pretreated with GSH, HK-156 (10 $\mu \mathrm{mol} / \mathrm{L})$, the mixture or 809 (10 $\mu \mathrm{mol} / \mathrm{L})$ for $20 \mathrm{~min}$ and then stimulated with LPS for $20 \mathrm{~min}$. Whole cell lysates were processed for Western blotting analysis using antibodies as indicated. (D) THP-1 cells were pretreated with GSH, HK-156 $(10 \mu \mathrm{mol} / \mathrm{L})$, the mixture or $809(10 \mu \mathrm{mol} / \mathrm{L})$ for $20 \mathrm{~min}$ and then stimulated with LPS for $16 \mathrm{~h}$. The cell culture media were collected and subjected to an ELISA for TNF $\alpha$. (E) HK-156 was incubated with 4 eq of GSH for 60 min at $37^{\circ} \mathrm{C}$, and the mixture was resolved by mass spectrometry. The molecular weights of the molecules are indicated. An arrow indicates the functional group of HK-156, which may react with thiol nucleophiles. $n=3$. Mean \pm SEM. ${ }^{c} P<0.01$ vs vehicle. ${ }^{f} P<0.01$ vs HK-156 $10 \mu \mathrm{mol} / \mathrm{L}$.

inhibit the LPS-induced transcriptional activity of NF-кB in a dose-dependent fashion. HK-156 significantly inhibited the LPS-stimulated production of proinflammatory cytokines in human monocytes through the inactivation of NF-kB, via suppressing the LPS-induced phosphorylation of TAK1. In addition, we showed in vivo that HK-156 inhibited LPS-stimulated TNFa secretion and enhanced survival in a mouse model of lethal LPS-induced sepsis.
To discover a novel NF- $\mathrm{KB}$ inhibitor, we established an NF-кB luciferase reporter system, the stably transfected cell line HEK293hTLR4/NF-kB-luc, which expresses TLR4, MD-2 and CD14. Using cell-based high-throughput screening with LPS as a stimulus, we found that the small molecule HK-156 could inhibit the LPS-induced transcriptional activity of NF-кB in a dose-dependent fashion (Figure 1C). Monocytes play a critical role in the pathogenesis of various infectious and 

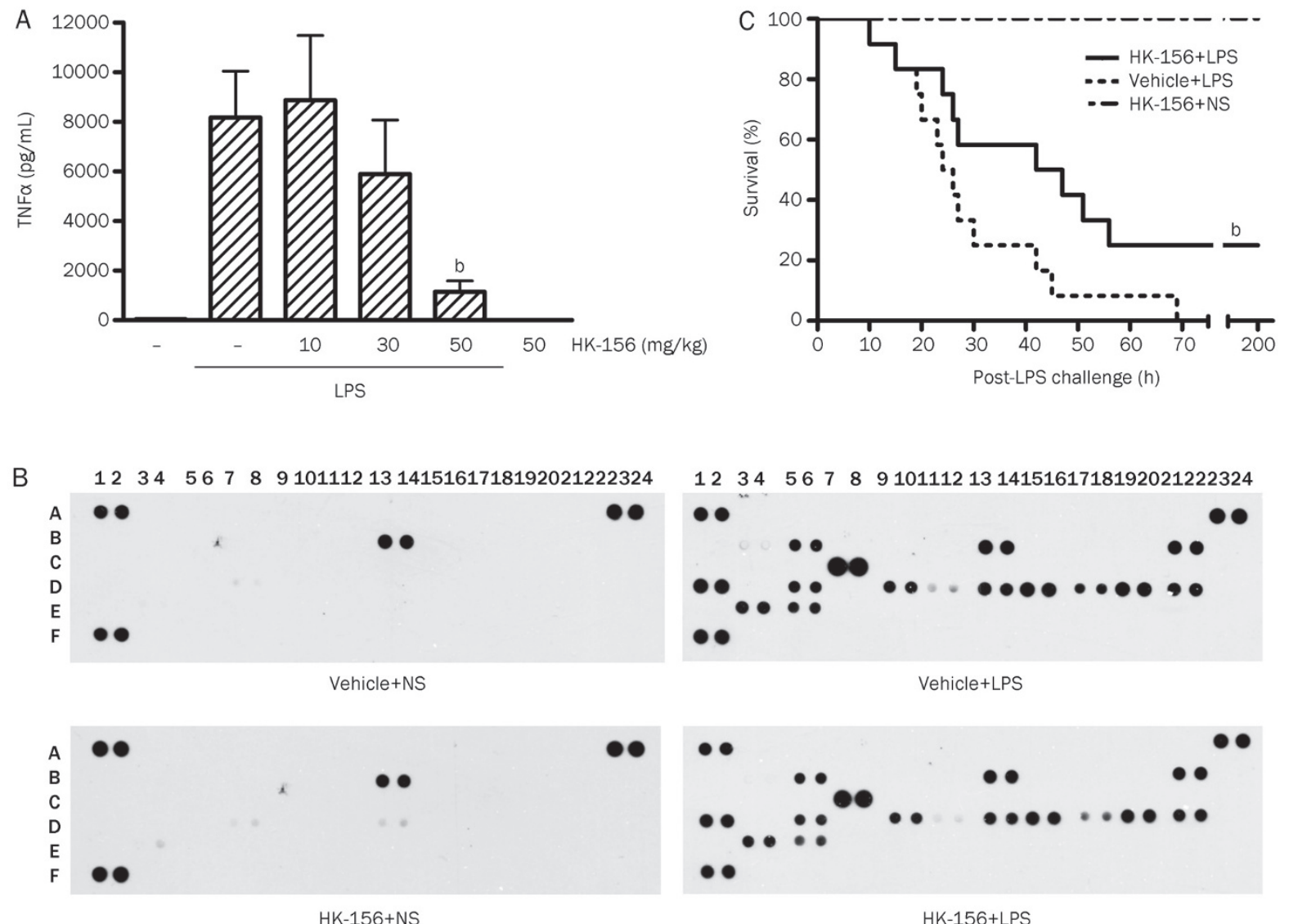

HK-156+LPS

\begin{tabular}{|c|c|c|c|c|c|c|c|c|c|c|c|c|}
\hline & 12 & 34 & 56 & 78 & 910 & 1112 & 1314 & 1516 & 1718 & 1920 & 2122 & 2324 \\
\hline A & POS & - & - & - & - & - & - & - & - & - & - & POS \\
\hline B & BLC & $\mathrm{C5a}$ & G-CSF & GM-CSF & $1-309$ & Eotaxin & sICAM-1 & INF-Y & IL-1 $\alpha$ & IL-1及 & IL-1ra & IL-2 \\
\hline C & IL-3 & IL-4 & IL-5 & IL-6 & IL-7 & IL-10 & IL-13 & IL-12p70 & IL-16 & IL-17 & IL-23 & IL-27 \\
\hline D & IP-10 & I-TAC & $\mathrm{KC}$ & M-CSF & $\mathrm{JE}$ & MCP-5 & MIG & MIP-1 $\alpha$ & MIP-1 $\beta$ & MIP-2 & RANTES & SD-1 \\
\hline $\mathrm{E}$ & TARC & TIMP-1 & $\mathrm{TNF} \alpha$ & TREM-1 & - & - & - & - & - & - & - & - \\
\hline
\end{tabular}

Figure 6. Effect of HK-156 on LPS-induced secretion of inflammatory cytokines and mortality in vivo. BALB/c mice (12 mice/group) were administered iv with the indicated doses of HK-156 (10,30, and $50 \mathrm{mg} / \mathrm{kg}$ body weight) or vehicle $2 \mathrm{~h}$ before ip administration of LPS (15 mg/kg body weight). (A) The serum level of TNF $\alpha$ was determined $2 \mathrm{~h}$ after the LPS or NS injection with ELISA assays. Results represent the mean \pm SEM of three independent experiments (using 12 animals per experimental group. Mean \pm SEM. ${ }^{b} P<0.05$ compared with LPS treated alone). (B) The mixture of equal volume of serum from each mouse per group $2 \mathrm{~h}$ after the LPS or NS injection was subjected to cytokine array analysis. The positions of the respective cytokines and controls on the array are shown below. (C) Survival was monitored every $1 \mathrm{~h}$ over the course of $200 \mathrm{~h}$. Experiments were performed three times using 12 animals per group and reported in a Kaplan-Meier survival curve. ${ }^{b} P<0.05$ vs Vehicle+LPS.

inflammatory diseases ${ }^{[28]}$. Thus, the human monocyte cell line THP-1 was employed to study the efficacy and mechanism of action of HK-156. LPS induced the release of many NF-KB targeted cytokines (Figure 1D), consistent with previously reported results ${ }^{[29]}$. However, HK-156 reduced the expression of these cytokines after treatment of the cells with LPS. IL-1 $\beta$, RANTES and TNFa were the most apparently attenuated. The incomplete attenuation might be explained by the fact that the expression of proinflammatory cytokines is not exclusively regulated by NF-KB but is also affected by the integration of several other transcription factors.

The inhibition of the production and release of proinflam- matory cytokines from LPS-stimulated THP-1 cells in a dose-dependent manner indicated that HK-156 significantly inhibited the transcription of cytokines TNFa and IL-1 $\beta$ at the mRNA level and then resulted in reduced secretion of cytokines at the protein level (Figure 2). HK-156 significantly impaired LPS-stimulated translocation of NF-kB into the nucleus and its binding with DNA concomitant with the phosphorylation and degradation of IкBa (Figure 3). It also inhibited the phosphorylation of IKK $\beta$ and TAK1 in THP-1 cells stimulated by LPS in a dose-dependent manner to almost the same degree seen for the transcriptional activation of NF-kB in HEK293hTLR4/NF-kB-luc cells (Figure 1C, 4A). All 
of these data suggested that HK-156 is an NF-KB inhibitor. It inhibited the LPS-induced phosphorylation of TAK1, resulting in IKK $\beta$ inactivation, and subsequently reduced the phosphorylation and degradation of IKBa, blocking the translocation of the NF- $\mathrm{kB}$ complex into the nucleus and binding to the $\mathrm{\kappa B}$ enhancer sequence of the targeted genes. As a consequence, HK-156 decreased the production and secretion of proinflammatory cytokines such as TNFa and IL-1 $\beta$ in THP-1 cells.

The impaired phosphorylation of TAK1 caused by HK-156 indicated that a molecule upstream of TAK1 in the LPSinduced NF- $\mathrm{KB}$ signaling pathway might be a potential target of HK-156. The activation of TAK1 is a prerequisite not only for the activation of IKK $\beta$ but also for the activation of MAPKs such as mitogen-activated protein kinase kinase 6 (MKK6, also known as MAP2K6), which is stimulated by LPS, which, in turn, phosphorylates JNK and p38 kinase $\mathrm{e}^{[20,30-32]}$. However, the activation of another MAPK kinase (ie, ERK) following TLR4 stimulation by LPS does not seem to require the activation of TAK1. It has been reported that LPS induced the activation of ERK in THP-1 cells, leading to the phosphorylation of Elk-1 and the expression of Erg-1, which acted together with independently activated NF-KB to induce gene expression ${ }^{[33]}$. The phosphorylation of IKK $\beta$ and MAPK p38 in THP-1 cells stimulated by LPS was weakened by HK-156 (Figure 4A, 4B), further showing that HK-156 might target a protein upstream of TAK1 within the LPS/TLR4/TAK1/NF-KB signaling pathway, perhaps by interfering with the protein-protein interaction between adapters. This information is consistent with the fact that the highly selective IKK $\beta$ inhibitor TPCA- $1^{[24]}$ did not inhibit the phosphorylation of TAK1 induced by LPS (data not shown). HK-156 might have no influence on the phosphorylation of ERK1/2 induced by LPS, and because activation of ERK is independent of NF-kB signaling, the influence of HK-156 on the phosphorylation of ERK1/2 induced by LPS might not affect the effect of HK-156 on NF-KB signaling. All of these results suggest that the inhibition of the LPS-induced production of proinflammatory mediators by HK-156 might occur through targeting a protein upstream of TAK1 and then downregulating the TAK1/IKK and TAK1/p38 MAPK pathways.

The release of proinflammatory cytokines induced by LPS through the activation of NF-kB signaling is the major pathological mechanism of sepsis ${ }^{[14]}$. Experimental models of sepsis have also shown increased levels of TNFa in the serum preceding organ failure ${ }^{[34]}$. TNFa is the major contributor to organ failure and death in the progression of sepsis ${ }^{[35]}$, and anti-TNF-mAb therapy (Afelimomab) in clinical trials has had a little positive effect ${ }^{[21]}$. During sepsis in vivo, the upregulation of proinflammatory cytokines initiates and contributes to organ dysfunction syndrome. The inhibition of the expression of these molecules may ameliorate inflammation. In our study, HK-156 protected mice from LPS-induced lethal toxicity in vivo (Figure 6C). This effect was accompanied by a decrease in the LPS-stimulated production of TNFa, demonstrating the anti-inflammatory potential of HK-156 in vivo. The increased survival of mice pretreated with HK-156 is in agreement with our in vitro experiments. Moreover, attenuation of many proinflammatory cytokines release besides TNFa induced by LPS in vivo showed that HK-156 might have better effect than anti-TNF-mAb. However, recent studies showed that the elevated serum level of a late mediator, high mobility group box 1 (HMGB1), is highly correlated with the lethal outcome of human sepsis ${ }^{[36,37]}$. The effect of HK-156 on sepsis might be further assessed based on levels of this mediator rather than the inhibition of the release of early proinflammatory cytokines.

Interestingly, we found that HK-156 inhibited the LPSstimulated phosphorylation of IKK $\beta$ at Ser177 and Ser181 in the T-loop but induced the phosphorylation of IKKa at Ser180 (Figure 4A). As a core element of NF-KB signaling, the IKK complex primarily consists of IKKa, IKK $\beta$ and the regulatory subunit IKK $\gamma / \mathrm{NEMO}^{[3]}$. Until the present study, the fact that IKK $\beta$ but not IKKa plays a key role in the activation of classic NF-KB signaling had been clearly elucidated ${ }^{[1]}$. The simultaneous blockage of the phosphorylation of IKK $\beta$ at Ser177 and Ser181 completely inhibits the transduction of NF-kB signaling ${ }^{[38]}$. The phosphorylation of both sites of IKK $\beta$ that is induced by LPS was blocked by HK-156, showing that HK-156 is an effective inhibitor of NF-kB signaling (Figure 4A). However, the function of IKKa in the activation of classic NF-кB signaling is still ambiguous and has not been clearly described to date ${ }^{[1]}$. There are two paradoxical conclusions that can be drawn regarding the role of IKKa in the activation of NF- $\mathrm{KB}$ signaling during the process of inflammation. Some reports demonstrated that activation of IKKa through phosphorylation was essential for the expression of cytokines induced by stimuli. Activation of IKKa, resulting in the phosphorylation of $\mathrm{p} 65$ and histones, gives rise to the positive regulation of transcriptional activation of $\mathrm{NF}-\mathrm{KB}^{[39-41]}$. In contrast, a negative regulatory function of IKKa in the activation of NF-kB signaling has also been reported ${ }^{[42,43]}$. Manipulations that inactivate IKKa cause the suppression of NF- $\mathrm{KB}$ activity by accelerating both the turnover of the NF-KB subunits RelA and c-Rel and their removal from proinflammatory gene promoters ${ }^{[22]}$. Liu et al also reported that proinflammatory stimuli induced the activation and translocation of IKKa into the nucleus and then phosphorylated PIAS1 [protein inhibitor of activated STAT1 (signal transducer and activator of transcription 1)] to restrict inflammation and immune response ${ }^{[43]}$. Based on the function of IKKa, the author further proposed that small molecules that could enhance the phosphorylation of PIAS1 by activating IKKa might prove effective in reducing inflammation ${ }^{[44]}$. Usually, the activation of the kinase can be induced only when both sites in the T-loop of IKK are phosphorylated ${ }^{[38]}$. However, the kinase will be partly activated when a single site is phosphorylated. The role of the phosphorylation site of IKK $\beta$ at Ser181 is more important than that at Ser177 ${ }^{[38]}$. As for IKKa, phosphorylation at Ser176 plays a critical role in NIK (NF-kB-inducing kinase)-induced nonclassical NF-KB signaling ${ }^{[45]}$ and the expression of interferon-a through the activation of interferon regulatory factor $3 / 7$ (IRF3/7) by $\mathrm{NIK}^{[46]}$. IKKa phosphorylated only at Ser180 has partial kinase 
activity $^{[46]}$. The phosphorylation of IKKa induced by HK-156 only at Ser180 might suggest that HK-156 can partially activate the kinase activity of IKKa (Figure 4A). In contrast, LPS could induce weak phosphorylation of IKKa at Ser180 but not at Ser176 in THP-1 cells (Figure 4A). The real function of the partial activation of IKKa by HK-156 and LPS in THP-1 cells needs to be further investigated, although the possible positive regulation of NF-KB by HK-156 was disproved by the finding that HK-156 alone did not induce the transcriptional activation of NF-KB and expression of proinflammatory cytokines.

Many natural products that are thiol-reactive compounds with Michael reaction acceptor groups have been reported to inhibit NF-kB signaling. Eriocalyxin B (Eri-B), an entkauranoid isolated from Isodon eriocalyx, can selectively block the binding between NF- $\mathrm{KB}$ and the response elements in a noncompetitive manner through its functional Michael reaction acceptor without affecting the nuclear translocation of the transcription factor ${ }^{[47]}$. Several diterpenoids isolated from Isodon rubescens have also been shown to impact the translocation of NF-KB from the cytoplasm to nuclei without affecting IкBa phosphorylation and degradation ${ }^{[48]}$. Caffeic acid phenethyl ester (CAPE), an active component of propolis from honeybees, was shown to directly inhibit the activity of IKK $\beta$ at $25 \mu \mathrm{mol} / \mathrm{L}$ without influencing the TNFa-induced phosphorylation of IKK $\beta$, in which the electrophilic Michael reaction acceptor might be involved ${ }^{[49]}$. Moreover, a cyclopentanone prostaglandin was found to inhibit the activity of IKK $\beta$ through the interaction of the thiol of cysteine 179 in IKK $\beta$ with a Michael reaction acceptor in the prostaglandin ${ }^{[50]}$. In our studies, HK-156 was shown to be more effective than CAPE and to inhibit LPS-induced NF-kB signaling dependent on the presence of the Michael reaction acceptor group. Furthermore, the effect of HK-156 is thiol dependent. Because HK-156 can attenuate the phosphorylation of TAK1 and IKK $\beta$ and the translocation of the NF- $\mathrm{KB}$ complex into the nucleus and the formation of the NF-kB-DNA complex in a dosedependent manner, it is not likely that HK-156 could inhibit the activity of IKK $\beta$ or binding of NF-kB with DNA. The cellular target of HK-156 might be a cysteine-containing protein upstream of TAK1 whose identity is still under investigation.

In summary, our study discovered that a novel synthetic small molecule HK-156 is a potent inhibitor of the LPS/ NF-kB signaling pathway. HK-156 potently inhibited the LPSinduced transcriptional activation of NF-кB. Morever, HK-156 could inhibit TNFa production, possibly through targeting a protein upstream of TAK1 that might contain cysteine, resulting in the inhibition of LPS-induced activation of NF-кB signaling in vitro in THP-1 monocytes. In addition, HK-156 could protect mice from LPS-induced lethality, accompanied by decreased TNFa production in vivo. Our study provides a novel NF-kB inhibitor with potential application for the treatment of sepsis. Furthermore, given the novel structure of HK-156, HK-156 might be used as a lead compound for developing new drugs for the treatment of sepsis and other inflammatory diseases.

\section{Acknowledgements}

The work was funded by State key Laboratory of Drug Research. We wish to express our sincere thanks to Ms Yuan ZHOU (Novartis Institutes for BioMedical Research, Shanghai, China) for her technical assistance. We also thank Xin-yan NI for animal studies.

\section{Author contribution}

Dr Kan DING and Dr You-hong HU designed the research; Jian-ping FANG, Jie LI, and Wen-feng LIAO performed the research; Yang LIU contributed new agents; Jian-ping FANG wrote the paper; Dr Kan DING revised the paper.

\section{Supplementary information}

Supplementary figures are available at website of Acta Pharmacologica Sinica on NPG.

\section{References}

1 Hayden MS, Ghosh S. Shared principles in NF-kappaB signaling. Cell 2008; 132: 344-62.

2 Vallabhapurapu S, Karin M. Regulation and function of NF-kappaB transcription factors in the immune system. Annu Rev Immunol 2009; 27: 693-733.

3 Huxford T, Ghosh G. A structural guide to proteins of the NF-kappaB signaling module. Cold Spring Harb Perspect Biol 2009; 1: a000075.

4 Pahl HL. Activators and target genes of Rel/NF-kappaB transcription factors. Oncogene 1999; 18: 6853-66.

5 Yamamoto Y, Gaynor RB. Role of the NF-kappaB pathway in the pathogenesis of human disease states. Curr Mol Med 2001; 1: 287 96.

6 Gerondakis S, Grumont R, Gugasyan R, Wong L, Isomura I, Ho W, et al. Unravelling the complexities of the NF-kappaB signalling pathway using mouse knockout and transgenic models. Oncogene 2006; 25: 6781-99.

7 Dong J, Jimi E, Zeiss C, Hayden MS, Ghosh S. Constitutively active NF-kappaB triggers systemic TNFalpha-dependent inflammation and localized TNFalpha-independent inflammatory disease. Genes Dev 2010; 24: 1709-17.

8 Ivanenkov YA, Balakin KV, Tkachenko SE. New approaches to the treatment of inflammatory disease: focus on small-molecule inhibitors of signal transduction pathways. Drugs R D 2008; 9: 397-434.

9 O'Neill LA. Targeting signal transduction as a strategy to treat inflammatory diseases. Nat Rev Drug Discov 2006; 5: 549-63.

10 Sarkar FH, Li Y, Wang Z, Kong D. NF-kappaB signaling pathway and its therapeutic implications in human diseases. Int Rev Immunol 2008; 27: 293-319.

11 Suffredini AF, Munford RS. Novel therapies for septic shock over the past 4 decades. JAMA 2011; 306: 194-9.

12 Bone RC, Grodzin CJ, Balk RA. Sepsis: a new hypothesis for pathogenesis of the disease process. Chest 1997; 112: 235-43.

13 Munford RS. Severe sepsis and septic shock: the role of gramnegative bacteremia. Annu Rev Pathol 2006; 1: 467-96.

14 Liu SF, Malik AB. NF-kappa B activation as a pathological mechanism of septic shock and inflammation. Am J Physiol Lung Cell Mol Physiol 2006; 290: L622-45.

15 Lu YC, Yeh WC, Ohashi PS. LPS/TLR4 signal transduction pathway. Cytokine 2008; 42: 145-51.

16 Sato S, Sanjo H, Takeda K, Ninomiya-Tsuji J, Yamamoto M, Kawai T, et al. Essential function for the kinase TAK1 in innate and adaptive 
immune responses. Nat Immunol 2005; 6: 1087-95.

17 Guha M, Mackman N. LPS induction of gene expression in human monocytes. Cell Signal 2001; 13: 85-94.

18 Kawai T, Akira S. The role of pattern-recognition receptors in innate immunity: update on Toll-like receptors. Nat Immunol 2010; 11: 373-84.

19 Miggin SM, O'Neill LA. New insights into the regulation of TLR signaling. J Leukoc Biol 2006; 80: 220-6.

20 Beutler B. Microbe sensing, positive feedback loops, and the pathogenesis of inflammatory diseases. Immunol Rev 2009; 227: 248-63.

21 Wheeler DS, Zingarelli B, Wheeler WJ, Wong HR. Novel pharmacologic approaches to the management of sepsis: targeting the host inflammatory response. Recent Pat Inflamm Allergy Drug Discov 2009; 3: 96-112.

22 Gilmore TD, Herscovitch M. Inhibitors of NF-kappaB signaling: 785 and counting. Oncogene 2006; 25: 6887-99.

23 Calzado MA, Bacher S, Schmitz ML. NF-kappaB inhibitors for the treatment of inflammatory diseases and cancer. Curr Med Chem 2007; 14: 367-76.

24 Bamborough P, Callahan JF, Christopher JA, Kerns JK, Liddle J, Miller $\mathrm{DD}$, et al. Progress towards the development of anti-inflammatory inhibitors of IKKbeta. Curr Top Med Chem 2009; 9: 623-39.

25 Leon CG, Tory R, Jia J, Sivak O, Wasan KM. Discovery and development of toll-like receptor 4 (TLR4) antagonists: a new paradigm for treating sepsis and other diseases. Pharm Res 2008; 25: 1751-61.

26 Barochia A, Solomon S, Cui X, Natanson C, Eichacker PQ. Eritoran tetrasodium (E5564) treatment for sepsis: review of preclinical and clinical studies. Expert Opin Drug Metab Toxicol 2011; 7: 479-94.

27 Abraham E. Nuclear factor-kappaB and its role in sepsis-associated organ failure. J Infect Dis 2003; 187: S364-9.

28 Robbins CS, Swirski FK. The multiple roles of monocyte subsets in steady state and inflammation. Cell Mol Life Sci 2010; 67: 2685-93.

29 Suzuki T, Hashimoto S, Toyoda N, Nagai S, Yamazaki N, Dong HY, et al. Comprehensive gene expression profile of LPS-stimulated human monocytes by SAGE. Blood 2000; 96: 2584-91.

30 Palsson-McDermott EM, O'Neill LA. Signal transduction by the lipopolysaccharide receptor, Toll-like receptor-4. Immunology 2004; 113: 153-62.

31 Landstrom M. The TAK1-TRAF6 signalling pathway. Int J Biochem Cell Biol 2010; 42: 585-9.

32 Hayden MS, Ghosh S. Signaling to NF-kappaB. Genes Dev 2004; 18 : 2195-224.

33 Guha M, O'Connell MA, Pawlinski R, Hollis A, McGovern P, Yan SF, et al. Lipopolysaccharide activation of the MEK-ERK1/2 pathway in human monocytic cells mediates tissue factor and tumor necrosis factor alpha expression by inducing Elk-1 phosphorylation and Egr-1 expression. Blood 2001; 98: 1429-39.

34 Tracey KJ, Cerami A. Tumor necrosis factor, other cytokines and disease. Annu Rev Cell Biol 1993; 9: 317-43.
35 Secher T, Vasseur V, Poisson DM, Mitchell JA, Cunha FQ, Alves-Filho $\mathrm{JC}$, et al. Crucial role of TNF receptors 1 and 2 in the control of polymicrobial sepsis. J Immunol 2009; 182: 7855-64.

36 Huang W, Tang Y, Li L. HMGB1, a potent proinflammatory cytokine in sepsis. Cytokine 2010; 51: 119-26.

37 Wang $\mathrm{H}$, Bloom $\mathrm{O}$, Zhang M, Vishnubhakat JM, Ombrellino M, Che J, et al. HMG-1 as a late mediator of endotoxin lethality in mice. Science 1999; 285: 248-51.

38 Delhase M, Hayakawa M, Chen $\mathrm{Y}$, Karin M. Positive and negative regulation of IkappaB kinase activity through IKKbeta subunit phosphorylation. Science 1999; 284: 309-13.

39 Yang F, Tang E, Guan K, Wang CY. IKK beta plays an essential role in the phosphorylation of RelA/p65 on serine 536 induced by lipopolysaccharide. J Immunol 2003; 170: 5630-5.

40 Anest V, Hanson JL, Cogswell PC, Steinbrecher KA, Strahl BD, Baldwin AS. A nucleosomal function for IkappaB kinase-alpha in NF-kappaBdependent gene expression. Nature 2003; 423: 659-63.

41 Yamamoto Y, Verma UN, Prajapati S, Kwak YT, Gaynor RB. Histone H3 phosphorylation by IKK-alpha is critical for cytokine-induced gene expression. Nature 2003; 423: 655-9.

42 Lawrence T, Bebien M, Liu GY, Nizet V, Karin M. IKKalpha limits macrophage NF-kappaB activation and contributes to the resolution of inflammation. Nature 2005; 434: 1138-43.

43 Liu B, Yang Y, Chernishof V, Loo RR, Jang H, Tahk S, et al. Proinflammatory stimuli induce IKKalpha-mediated phosphorylation of PIAS1 to restrict inflammation and immunity. Cell 2007; 129: 90314.

44 Liu B, Shuai K. Targeting the PIAS1 SUMO ligase pathway to control inflammation. Trends Pharmacol Sci 2008; 29: 505-9.

45 Ling L, Cao Z, Goeddel DV. NF-kappaB-inducing kinase activates IKKalpha by phosphorylation of Ser-176. Proc Natl Acad Sci U S A 1998; 95: 3792-7.

46 Wang RP, Zhang M, Li Y, Diao FC, Chen D, Zhai Z, et al. Differential regulation of IKK alpha-mediated activation of IRF3/7 by NIK. Mol Immunol 2008; 45: 1926-34.

47 Leung CH, Grill SP, Lam W, Gao W, Sun HD, Cheng YC. Eriocalyxin B inhibits nuclear factor-kappaB activation by interfering with the binding of both $\mathrm{p} 65$ and $\mathrm{p} 50$ to the response element in a noncompetitive manner. Mol Pharmacol 2006; 70: 1946-55.

48 Leung CH, Grill SP, Lam W, Han QB, Sun HD, Cheng YC. Novel mechanism of inhibition of nuclear factor-kappa B DNA-binding activity by diterpenoids isolated from Isodon rubescens. Mol Pharmacol 2005; 68: 286-97.

49 Lee Y, Shin DH, Kim JH, Hong S, Choi D, Kim YJ, et al. Caffeic acid phenethyl ester-mediated Nrf2 activation and IkappaB kinase inhibition are involved in NFkappaB inhibitory effect: structural analysis for NFkappaB inhibition. Eur J Pharmacol 2010; 643: 21-8.

50 Rossi A, Kapahi P, Natoli G, Takahashi T, Chen Y, Karin M, et al. Antiinflammatory cyclopentenone prostaglandins are direct inhibitors of IkappaB kinase. Nature 2000; 403: 103-8. 